\title{
Short muscles of the hand and foot in Laonastes aenigmamus (Rodentia: Diatomyidae) and some other rock-dwellers
}

\author{
Petr P. Gambaryan \& Olga V. Zherebtsova*
}

\begin{abstract}
The short muscles of the hand and foot in the relict rock rat Laonastes aenigmamus Jenkins et al., 2005 (Rodentia: Diatomyidae) were studied for the first time. Some other rock-dwellers, Ctenodactylus gundi, Chinchilla lanigera, Ochotona macrotis, as well as Ochotona dauurica, inhabiting the plain landscapes, were also included in the morphological analysis for comparative purposes. In spite of the different localities of pikas, the structure of the short muscles of the hand and foot in both species of Ochotona is practically identical. At the same time the pikas differ substantially from the investigated rodents by a number of features of the short muscles: by the absence of the mm. palmaris brevis and add. digiti secundi in the hand and $\mathrm{m}$. abd. metatarsi $\mathrm{V}$ in the foot; by the absence of the typical mm. lumbricales in the hand and the whole absence of these muscles in the foot; by the presence only one belly of the $\mathrm{m}$. abd. digiti quinti in the hand instead of two bellies in rodents. In all studied forms, the structure of the $\mathrm{m}$. add. digiti quinti in the hand and the $\mathrm{mm}$. interossei both in the hand and foot, are characterized by a great similarity. Among the three investigated rodents, the most essential differences of the short muscles are connected with the reduction of the first fingers in the hand and foot in Ctenodactylus and Chinchilla. It was indicated that in Laonastes the state of the $\mathrm{mm}$. lumbricales is evidently the most primitive.
\end{abstract}

KEY WORDS: Chinchilla, Ctenodactylus, Laonastes, Ochotona, short muscles of the hand and foot.

Petr P. Gambaryan [gambarpp@yandex.ru], Olga V. Zherebtsova [hedgol@yandex.ru], Zoological Institute of the Russian Academy of Sciences. Universitetskaya emb. 1, Saint Petersburg 199034, Russia.

\section{Короткие мышцы кисти и стопы у Laonastes aenigmamus (Rodentia: Diatomyidae) и некоторых других скальных обитателей}

\author{
П.П. Гамбарян, О.В. Жеребцова
}

\begin{abstract}
РЕЗЮМЕ. Впервые проведено изучение коротких мышц кисти и стопы у реликтовой скальной крысы Laonastes aenigmamus Jenkins et al., 2005 (Rodentia: Diatomyidae). В сравнительный морфологический анализ включены и другие обитатели скал: Ctenodactylus gundi, Chinchilla lanigera, Ochotona macrotis так же, как и Ochotona dauurica, населяющая равнинные ландшафты. Несмотря на различные местообитания пищух, строение коротких мышц кисти и стопы у двух видов Ochotona практически идентично. В то же время по ряду особенностей коротких мышц пищухи существенно отличаются от исследованных грызунов: отсутствием $\mathrm{mm}$. palmaris brevis и add. digiti secunda в кисти и $\mathrm{m}$. abd. metatarsi $\mathrm{V}$ в стопе; отсутствием типичных mm. lumbricales в кисти и полным отсутствием этих мышц в стопе; наличием только одного брюшка m. abd. digiti quinti в кисти вместо двух у грызунов. У всех изученных форм строение $\mathrm{m}$. adductor digiti quinti в кисти и mm. interossei как в кисти, так и в стопе характеризуется большим сходством. Наиболее существенные различия в строении коротких мышц у трех исследованных грызунов связаны с редукцией первых пальцев на кисти и стопе у Ctenodactylus и у Chinchilla. Показано, что у Laonastes состояние mm. lumbricales, по-видимому, наиболее примитивное.
\end{abstract}

КЛЮЧЕВЫЕ СЛОВА: Chinchilla, Ctenodactylus, Laonastes, Ochotona, короткие мышцы кисти и стопы.

\section{Introduction}

Recently described relict rodent Laonastes aenigmamus Jenkins et al., 2005 (hereafter Laonastes) (Rodentia: Diatomyidae) inhabits the rocky landscapes in Laos (Jenkins et al., 2005). These habitats are characterized by certain attractive conditions: first, there are

* Corresponding author lots of plants among the rocks that would dry out in open landscapes; second, it is easier to find cover from predators under the rock debris. It is quite possible that Laonastes is capable of jumps from one stone to another, rescuing from predators. In this connection, the short muscles of the hand and foot in Laonastes were studied to reveal the specific features of their structure and work during the locomotion. 


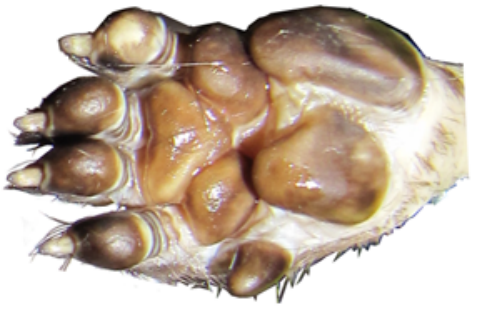

A

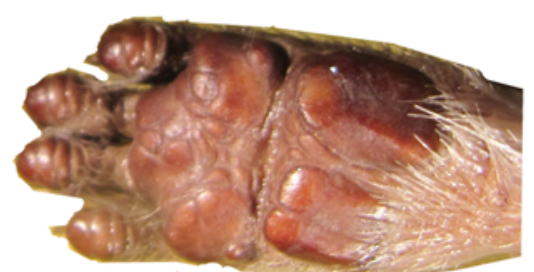

B

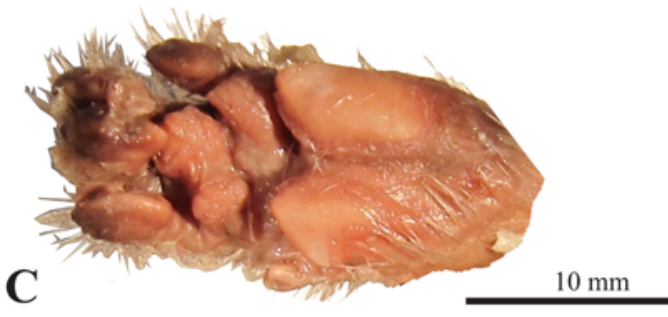

$\mathbf{A}^{\prime}$

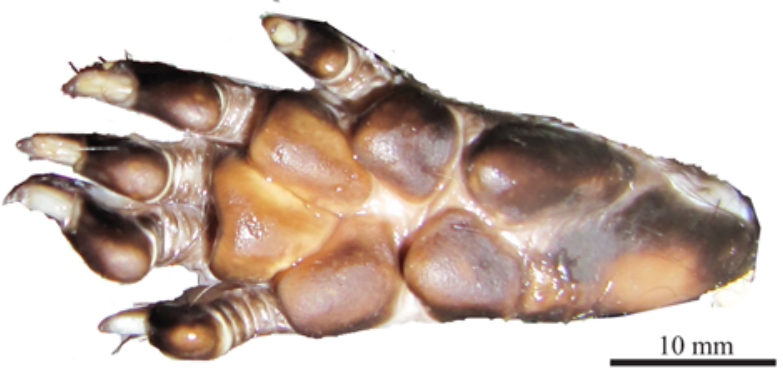

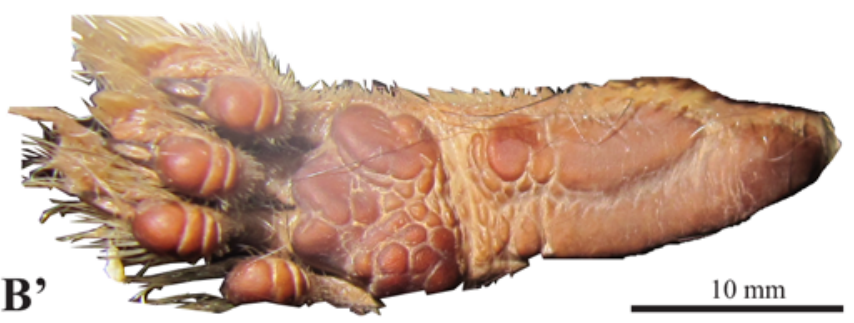

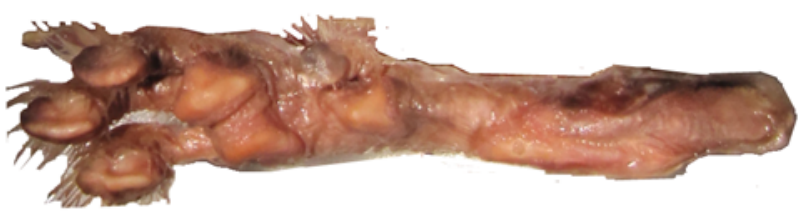

$C^{\prime}$

$10 \mathrm{~mm}$
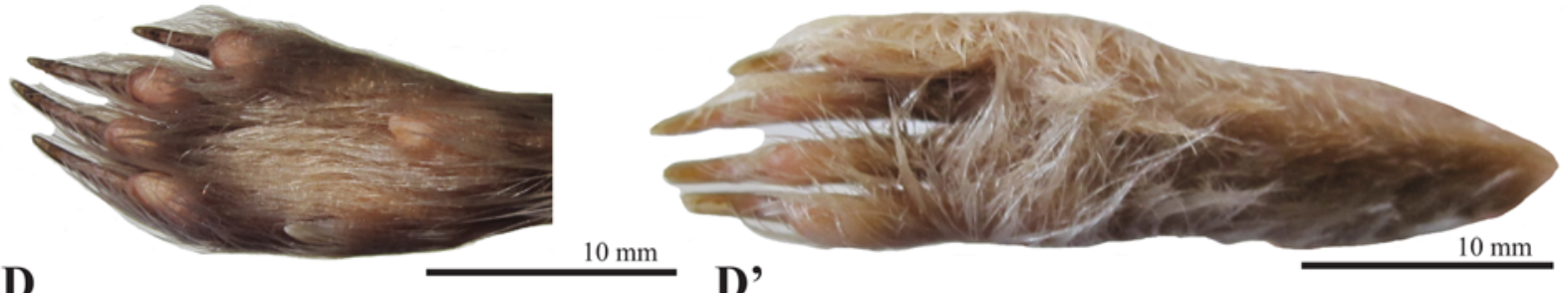

D'

Figure 1. The hand (left, A-D) from the volar side and the foot (left, $\mathrm{A}^{\prime}-\mathrm{D}^{\prime}$ ) from the plantar side: $\mathrm{A}, \mathrm{A}^{\prime}$ - Laonastes aenigmamus; B, B' - Ctenodactylus gundi; C, C' - Chinchilla lanigera; D, D' - Ochotona dauurica.

Ctenodactylus gundi Rothmann, 1776 (hereafter Ctenodactylus) (Rodentia: Ctenodactylidae) from North Africa, Chinchilla lanigera Bennett, 1829 (hereafter Chinchilla) (Rodentia: Chinchillidae) from South America, Ochotona macrotis Günther, 1875 (hereafter Ochotona) (Lagomorpha: Ochotonidae) from Asia, as well as Laonastes, are rock dwelling forms and probably similar to him on their locomotor adaptations. Therefore, these animals were also included in the morphological analysis of the short muscles of the hand and foot for comparison with Laonastes. Ochotona dauurica Pallas, 1776, inhabiting the plain landscapes, was also studied since for analysis of the adaptive specialization both ecological forms of Ochotona must be considered.

On the other side, at present Ctenodactylus and Chinchilla belong to different infraorders, Ctenodactylomorphi and Hystricognathi, respectively (Dieterlen, 2005; Woods \& Kilpatrick, 2005). Laonastes was brought closer together with one or another of these groups by different authors (Jenkins et al., 2005; Dawson et al., 2006; Huchon et al., 2007). At the same time Ochotona macrotis, in contrast with previous three forms, is the representative of another order, Lagomorpha, though it is characterized by a similar size of body and mode of life (Hoffmann \& Smith, 2005).

In the structure of the hand and foot of the three studied rodents there are a number of common features. First, the structure of their calluses, strongly protruding on the volar side of the hand and the plantar side of the foot, attracts the attention (Fig. $1 \mathrm{~A}-\mathrm{C}^{\prime}$ ). Besides finger calluses, the well developed pads are located at the bases of the hand claws. During the animals landing on the stones, just these finger pads are apparently the first to touch the surface and keep the paws of rodents from slipping.

In Ochotona, in contrast with investigated rodents, a principally different adaptation is observed. Its hands 
and feet are covered by coarse hairs that similarly to calluses prevents probably from slipping during the animals movement in the rocky landscapes (Fig. 1D, D').

A number of long and short muscles control the movements of the hand and foot. Since the long muscles were described separately (Gambaryan et al., 2013), in this work, the descriptions of actually hand and foot muscles and their comparative analysis were conducted. The morphofunctional features of the short muscles will be discussed in the next communication.

All studied forms of mammals are regarded in concordance with the classification after Wilson and Reeder (2005).

\section{Material and methods}

Three species of Rodentia and two species of Lagomorpha from the collections of the Zoological Institute of the Russian Academy of Sciences (ZIN, Saint Petersburg) were investigated: the Laotian rock rat, Laonastes aenigmamus Jenkins et al., 2005 ( $n=2$; ZIN 99491, 99496); the gundi, Ctenodactylus gundi Rothmann, 1776 ( $n=1$; ZIN 6641); the long-tailed chinchilla, Chinchilla lanigera Bennett, $1829(n=2$; ZIN 102069 (field numbers - 576a, 576b)); the Daurian pika, Ochotona dauurica Pallas, $1776(n=2$; ZIN $102070(262,264))$ and the large-eared pika, Ochotona macrotis Günther, 1875 ( $n=1$; ZIN 102071 (240)). Adult specimens were preserved in $70^{\circ}$ ethanol or $5 \%$ formalin. The short muscles of the hand and foot were examined with a binocular stereomicroscope Leica MZ6 using the total preparations.

\section{Results}

Because the structure of the short muscles of the hand and foot in both species of pikas are identical, their descriptions are considered as common attribute of the genus Ochotona.

\section{Short muscles of the hand}

M. palmaris brevis (Fig. 2). In Laonastes, there are the well-developed prepollex and the os pisiforme. From their surfaces, the muscle fibers, which are probably homologous to the $\mathrm{m}$. palmaris brevis, originate and run to pads of the pulvini carpales (Fig. 2A).

In Ctenodactylus, outside of all the actually hand muscles, over the top of the os pisiforme there is a sesamoid. From its distal end, the first muscle bundle goes to the inner surface of the skin of the proximal lateral callus (Fig. 2B). From the medial side of the external fascia of final tendon of the $\mathrm{m}$. flexor digitorum profundus, the muscle bundle comes to the second proximal callus. It seems likely that these two independent muscles are homologous to the m. palmaris brevis.

In Chinchilla, above the os pisiforme, the thickening of the connective tissue is observed, but sesamoid, like that in Ctenodactylus, is not developed. However, in Chinchilla, just like in Ctenodactylus, from this thickening and from the internal surface of the callus cover, the muscle bundles pass from right to left (Fig. 2C). Besides, the muscle bundles (both the longitudinal to the first digit, and transversal in the thickness of the medial callus) run from the prepollex, locating on the medial side of the hand.

In Ochotona, this muscle is absent.

M. abductor digiti quinti (Figs. 2-4). Besides two homologues of the $\mathrm{m}$. palmaris brevis described above, in all the three species of rodents, there is another superficial muscle, locating deeper than the $\mathrm{m}$. palmaris brevis. It originates by two independent bellies: one goes from the distal edge of the prepollex, and the second belly begins from the top of the os pisiforme, and both converge into a single tendon (Fig. 2A', B', $\mathrm{C}^{\prime}$ ). The latter is inserted on the proximal end of the lateral side of the first phalanx of digit $\mathrm{V}$.

In Ochotona, there is only one belly, going from the os pisiforme and terminating by two thin tendons (Figs. 3 , 4D). To medial of them, the tendinous brunch extends from the space between the fifth and fourth terminal tendons of the $\mathrm{m}$. fl. digitorum profundus. This brunch is apparently homologous to the $\mathrm{mm}$. lumbricales. In the result all three tendons fuse together over the metacarpo-phalangeal sesamoids of digit $\mathrm{V}$ and form its typical perforating tendon.

Mm. lumbricales (Figs. 2-4). In all the three species of rodents, besides usual connection with the tendon of the $\mathrm{m}$. fl. digitorum profundus, these muscles have more or less strong connection with the tendons of the $\mathrm{m}$. fl. digitorum sublimis.

In Laonastes, from the lateral side of a common plate of the $\mathrm{m}$. fl. digitorum profundus, the muscle belly begins, which is also attached to the lateral tendon of the $\mathrm{m}$. fl. digitorum sublimis (Fig. 2A'). On the surface of the latter, two tendons are soon formed. One of them is firmly linked to a common plate of the m. fl. digitorum profundus, and the second tendon is inserted on the final tendon of the $\mathrm{m}$. fl. digitorum sublimis to digit IV from the medial side. These two tendons converge to the tectum above the metacarpo-phalangeal sesamoids of digit $\mathrm{V}$, and bifurcate again under them.

A similar structure is observed in a typical final tendon of the $\mathrm{m}$. fl. digitorum sublimis, which passes under the tendon of the $\mathrm{m}$. fl. digitorum profundus, bifurcating over the metacarpo-phalangeal sesamoids. Then these branches interflow again into a single tendon, inserting on the plantar side of the proximal end of the second phalanx.

On the medial surface of the common plate and on the tendon of the $\mathrm{m}$. fl. digitorum profundus to the second digit, there is the second muscle belly of the $\mathrm{mm}$. lumbricales. Its final tendon is inserted on the superficial fascia, covering the tendon of the $\mathrm{m}$. fl. digitorum profundus to digit II. Besides, three bellies of the actual $\mathrm{mm}$. lumbricales originate in the interspaces between the tendons of the $\mathrm{m}$. fl. digitorum profundus to digits II-III, III-IV, and IV-V, and are inserted on 

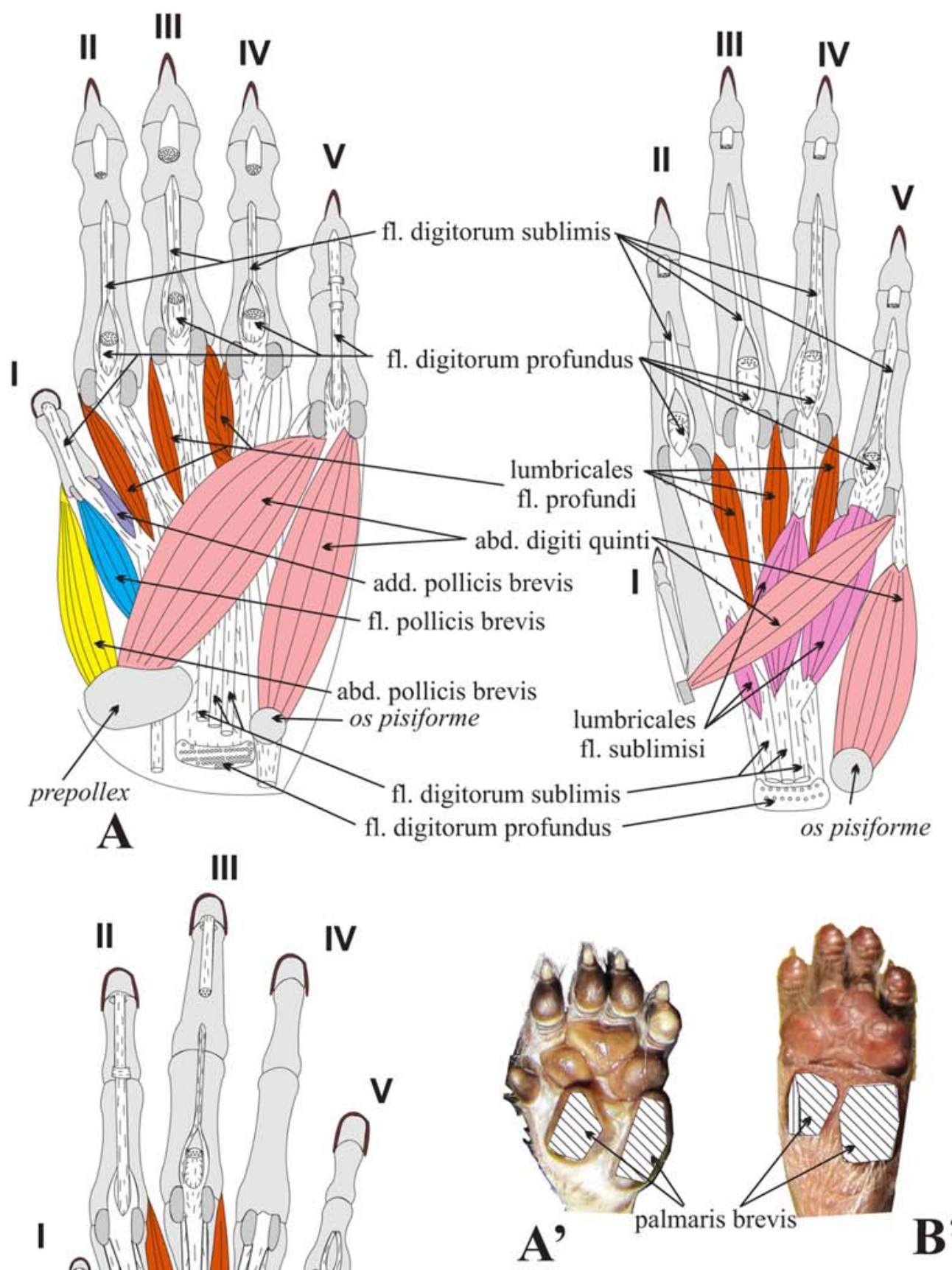


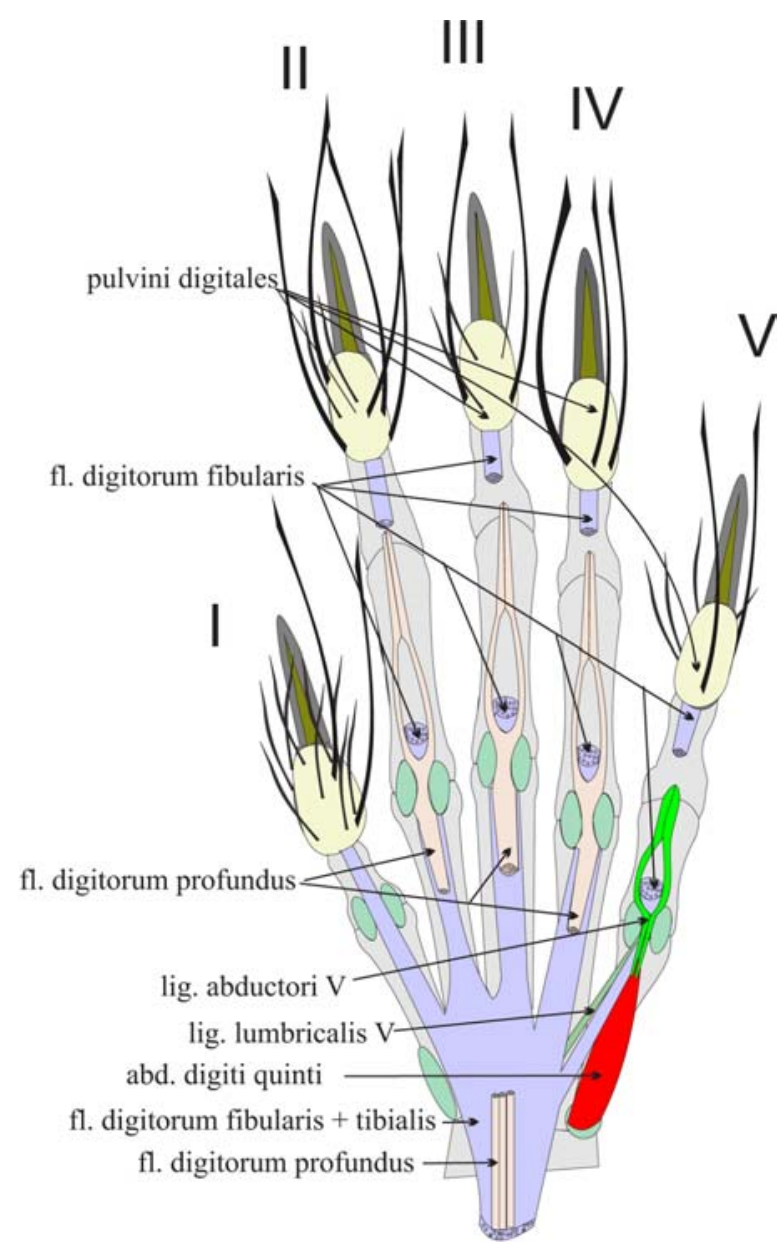

Figure 3. The muscles of the hand (left) from the volar side (the superficial layer) in Ochotona dauurica.

the fasciae, enveloping the tendons of the m. fl. digitorum profundus to digits II-IV.

In Ctenodactylus, after the removal of the m. palmaris brevis, two layers of the $\mathrm{mm}$. lumbricales are observed (Fig. 2B'). The first of them is related to the tendons of the $\mathrm{m}$. fl. digitorum sublimis, and another is connected with the tendons of the $\mathrm{m}$. fl. digitorum profundus. In the first layer, the most powerful belly originates a little distal to the level of the os pisiforme on the tendon of the $\mathrm{m}$. fl. digitorum sublimis to digit V, and soon forms the perforating tendon. The second belly originates a little distal to the level of the os pisiforme on the tendon of the $\mathrm{m}$. fl. digitorum sublimis to digit IV. The third belly is still in a quite rudimentary condition. It begins above the level of the os pisiforme and terminates on the tendon of the $\mathrm{m}$. fl. digitorum sublimis to digit II.

In Chinchilla, the transformation of the mm. lumbricales is a more advanced than that in Laonastes, but is not so complex as in Ctenodactylus (Fig. 2C'). Most lateral part of the belly originates from the lateral side of a common plate of the $\mathrm{m}$. fl. digitorum profundus. Simultaneously, it begins from the final tendon of the $\mathrm{m}$. fl. digitorum sublimis to digit IV. Then this belly goes to the metacarpo-phalangeal sesamoids of digit $\mathrm{V}$ and terminates on it by a typical perforated tendon.

In Ochotona, between the terminal tendons of the m. fl. digitorum profundus to digits IV and $\mathrm{V}$, the tendon is only observed, which is probably homologous to the typical mm. lumbricales (Figs. 3, 4D).

Mm. adductor digiti quinti and adductor digiti secundi (Fig. 4). In all the three rodents, the both muscles originate on the middle connective-tissue plate of the hand, and also on a common volar aponeurosis of all the mm. interossii. These muscles terminate on the proximal ends of the first phalanxes of digits $\mathrm{V}$ (from the medial side) and II (from the lateral side).

In Ochotona, the origin and termination of the $\mathrm{m}$. add. digiti quinti are the same as in investigated rodents but the m. add. digiti secundi is absent (Fig. 4D).

Mm. abductor, flexor, and adductor pollicis brevis (Figs. 2, 4). In Laonastes, these three muscles interflow into a single muscle, which originates deeper than the m. abd. digiti quinti on the distal margin of the prepollex (Figs. 2A', 4A). Its external fibers terminate on the medial edge of the first phalanx, and its lateral fibers insert on the lateral edge of same phalanx. The part of the longitudinal fibers reaches also the claw phalanx, inserting there under the tendon of the $\mathrm{m}$. fl. digitorum profundus to the first digit. According their direction, the muscle bundles mentioned above can be conventionally divide into three muscles: abductor, adductor and flexor pollicis brevis, respectively.

In Ctenodactylus, all these muscles are absent since the first digit is rudimentary.

In Chinchilla, the first finger is weaker developed than that in Laonastes, however there are all the three muscles, providing its mobility (Fig. 4C).

In Ochotona, there are only the $\mathrm{m}$. fl. pollicis brevis and the $\mathrm{m}$. add. pollicis brevis (Fig. 4D). The tendon of the latter is inserted on the fasciae near the basis of the pulvinus digitalis.

Mm. interossei (Fig. 4). In all studied rodents and Ochotona, there are eight these muscles: by two for each of four lateral digits. M. interossei lateralis of digit $\mathrm{V}$ begins on the distal surface of the os pisiforme. Other muscles originate from a general volar aponeurosis attached to the os carpalia, and on the volar surface of the metacarpales II-V. Mm. interossei terminate by tendons that bypass the metacarpo-phalangeal sesamoids and are infused into the extensor tendons. Only in Chinchilla, the $\mathrm{m}$. interossei lateralis of the first digit is inserted on the metacarpo-phalangeal sesamoids, and it is rather similar with the $\mathrm{m}$. fl. pollicis brevis.

In all investigated forms, the $\mathrm{mm}$. interossei before their insertions are infused into the tendons of the long digit extensors ( $\mathrm{mm}$. extensor digitorum communis and 


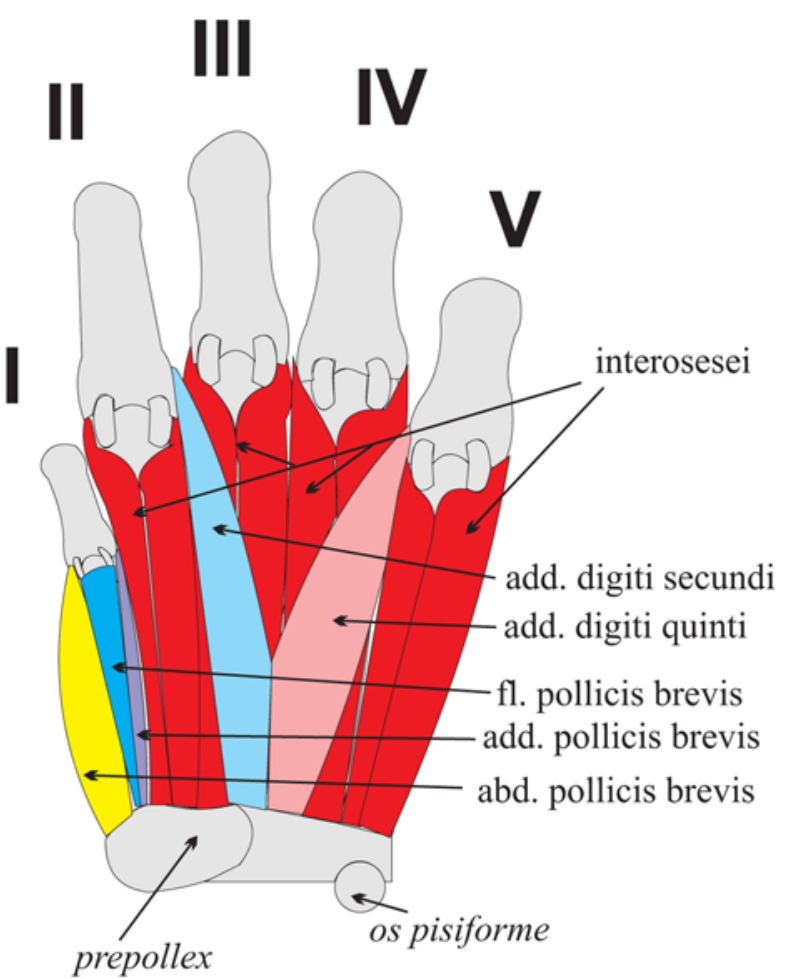

A

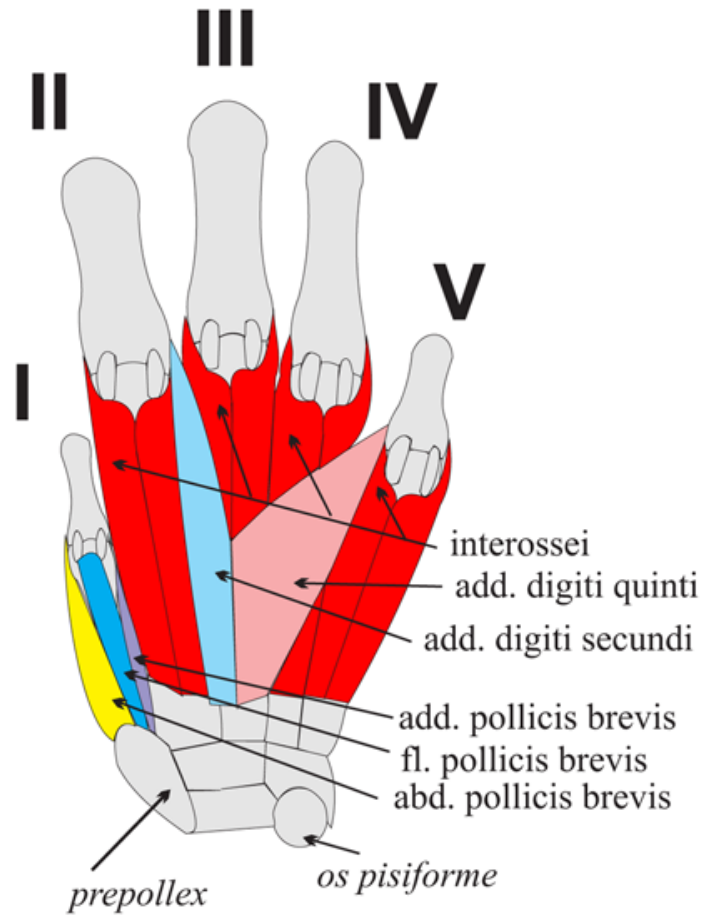

C

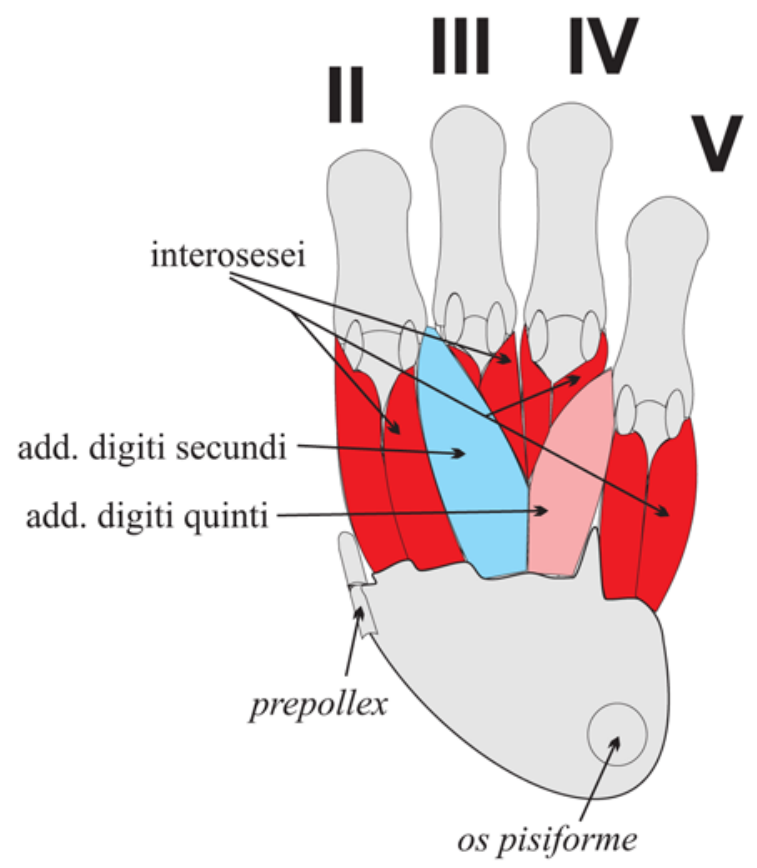

B

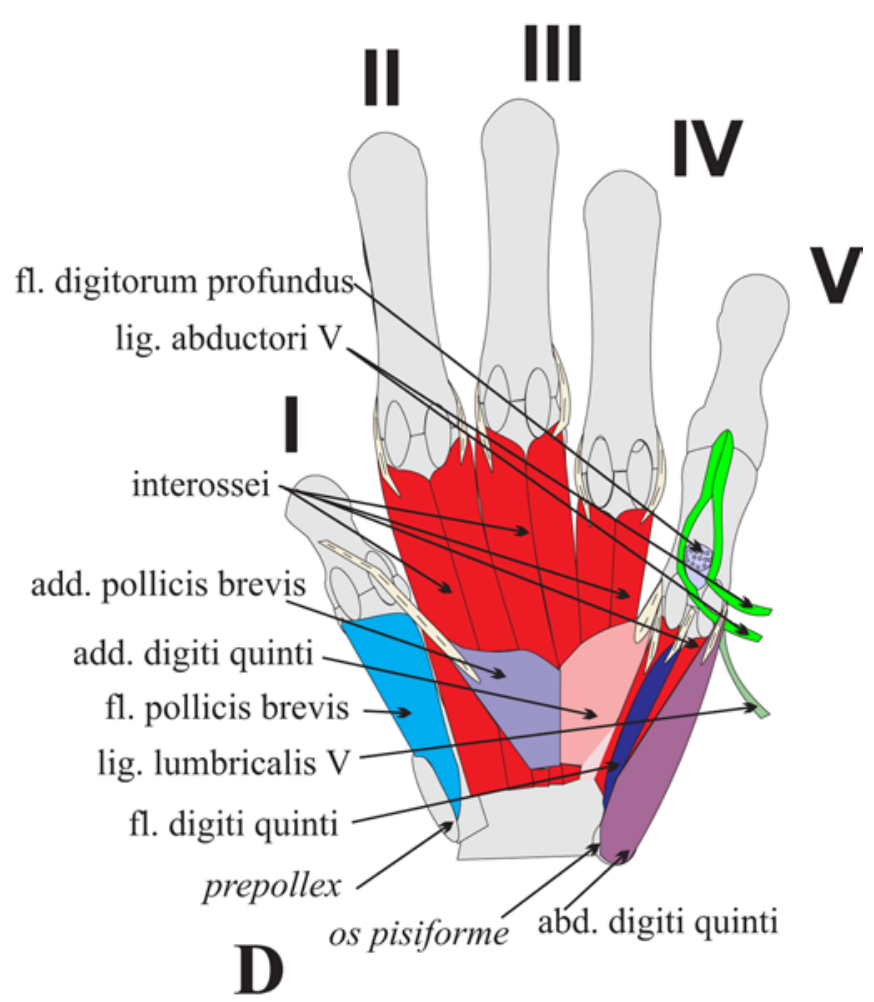

Figure 4. The muscles of the hand (left) from the volar side (the third layer): A — Laonastes aenigmamus; B — Ctenodactylus gundi; C - Chinchilla lanigera; D - Ochotona dauurica. 
lateralis, and m. ext. pollicis longus). In Laonastes, Chinchilla, and Ochotona, after the fusion, these tendons terminate directly on the proximal ends of the dorsal side of the second phalanxes of digits II-V. In Ctenodactylus, these tendons are inserted on the sesamoids, which are also attached by a special cord to the same phalanx. From these sesamoids (or from the attachments of the extensor tendons on the second phalanxes) the cords (ligamentum dorsalis) pass to the claw phalanxes on both of their surfaces.

\section{Short muscles of the foot}

M. extensor digitorum brevis (Fig. 5). In Laonastes and Ctenodactylus, it originates from the dorsal part of the distal end of the heel bone and runs by two tendons to digits II and III (Fig. 5A, B). These tendons infuse in the appropriate tendons of the $\mathrm{m}$. ext. digitorum longus, which terminate on special sesamoids in the joint capsules between the first and second phalanxes of digits II and III. The tendons of the $\mathrm{mm}$. interossei approach from the right and left to the same sesamoids. The very joint capsules thicken in front and particularly firmly attached to the dorsal part of the proximal end of the second phalanxes. From the edge of these attachments, a loose connective-tissue subcutaneous plate goes to the bases of the paries cornea, and the elastic cords (ligamentum dorsalis) pass to the bases of claw phalanxes on both sides.

In Chinchilla, the m. ext. digitorum brevis begins by two separate abdomens located between the proximal ends of the Mt. V and IV, as well as the Mt. IV and III (Fig. 5C). They terminate like those in the previous two species.

In Ochotona, this muscle originates like that in Laonastes and Ctenodactylus, however then it forms three tendons, which pass from the deep to the terminal tendons of the m. ext. digitorum longus at the level of metacarpo-phalangeal joints of digits II-IV (Fig. 5D). Their terminal insertions are the same as those in rodents.

M. flexor digitorum brevis (Fig. 6). In Laonastes, the origin of this muscle presents the final tendon of the m. plantaris (Fig. 6A). Further this tendon expands, and at the level of the distal part of the first metatarsal callus the muscle fibers are appeared on it. From the external surface of these fibers, the tendinous retractors to the bases of the calluses (two pulvini carpales and three pulvini metacarpales) separate. The muscular abdomen itself soon forms three perforating tendons to the three middle digits, which below the metatarso-phalangeal sesamoids bifurcate. The muscle terminates under the tendons of the $\mathrm{m}$. fl. digitorum fibularis on the plantar surface of the proximal end of the second phalanxes of the respective digits II-IV.

In Ctenodactylus, the muscle completely transforms into a tendinous plate, terminating by four flat tendons on the metatarso-phalangeal sesamoids (Fig. 6B). On the internal surface of this plate, the four weak muscu- lar abdomens appear, which terminate by their tendons, as well as the four perforating tendons. With these tendons from the surface, the flat tendons mentioned above grow together. The muscular abdomens on the internal surface of the described muscle are closely related to the $\mathrm{mm}$. lumbricales.

In Chinchilla, the muscle also completely transforms into a tendinous plate. On the proximal half of its plantar surface, the pulvinus tarsalis is attached (Fig. 6C). Further, the tendon to the pulvinus metatarsalis of digit V separates, which also has a branch to the lateral side of the proximal end of the first phalanx of digit $\mathrm{V}$. Then three perforating tendons to digits II-IV separate, from which the tendinous retractors go to the pulvini metatarsales: one passes to digits IV-V, and the another — to digit II. Besides, from the total flexor tendon, the tendinous plates also go to the pulvinus metatarsalis of digit IV.

In Ochotona, this muscle, as an immediate continuation of the $\mathrm{m}$. plantaris tendon, passes on the foot and forms a common tendinous plate (Fig. 6D). The latter divides into four typical perforating tendons, going to four digits.

M. quadratus plantae (Fig. 6). In Laonastes, it originates on the latero-distal part of the plantar surface of the os calcaneus and inserts onto a common tendinous plate of the $\mathrm{mm}$. fl. digitorum fibularis and tibialis.

In Chinchilla, the origin of the muscle additionally extends on the lateral side of the proximal end of the Mt. V (Fig. 6C). Its insertion is like that in Laonastes.

In Ctenodactylus and Ochotona, this muscle is absent.

Mm. lumbricales (Fig. 6). In Laonastes, the first abdomen of the muscle originates between the tendons of the $\mathrm{m}$. fl. fibularis to the first and second digits (Fig. $6 \mathrm{~A})$. The tendon of the muscle goes to the medial metatarso-phalangeal sesamoid and there merges with the tendon of the mm. interossei. The latter merges with the tendon of the $\mathrm{m}$. ext. digitorum longus onto the inter-phalangeal sesamoid. The second and third abdomens originate between the tendons of the $\mathrm{m}$. fl. fibularis to the second and third digits. The second abdomen inserts onto the tendon of the $\mathrm{m}$. fl. digitorum brevis to the third digit, and the third abdomen - onto the inter-phalangeal joint capsule from the medial side and tendon of the mm. interossei. The fourth and fifth abdomens originate between the tendons of the $\mathrm{m}$. $\mathrm{fl}$. fibularis to the third and fourth digits, and insert like the previous two abdomens. However, the sixth abdomen on digit IV originates on the lateral surface of the tendon of the $\mathrm{m}$. fl. fibularis to digit V. It inserts as a typical perforating tendon, which bifurcates at the level of the metatarso-phalangeal sesamoids and terminates on the plantar side of the second phalanx of digit $\mathrm{V}$.

In Ctenodactylus, one muscle belly originates from the medial side of a total plate of the $\mathrm{mm}$. fl. digitorum fibularis and tibialis at the level of the proximal ends of the metatarsal bones (Fig. 6B). In the middle of this abdomen, the tendon of the second abdomen passes, the 


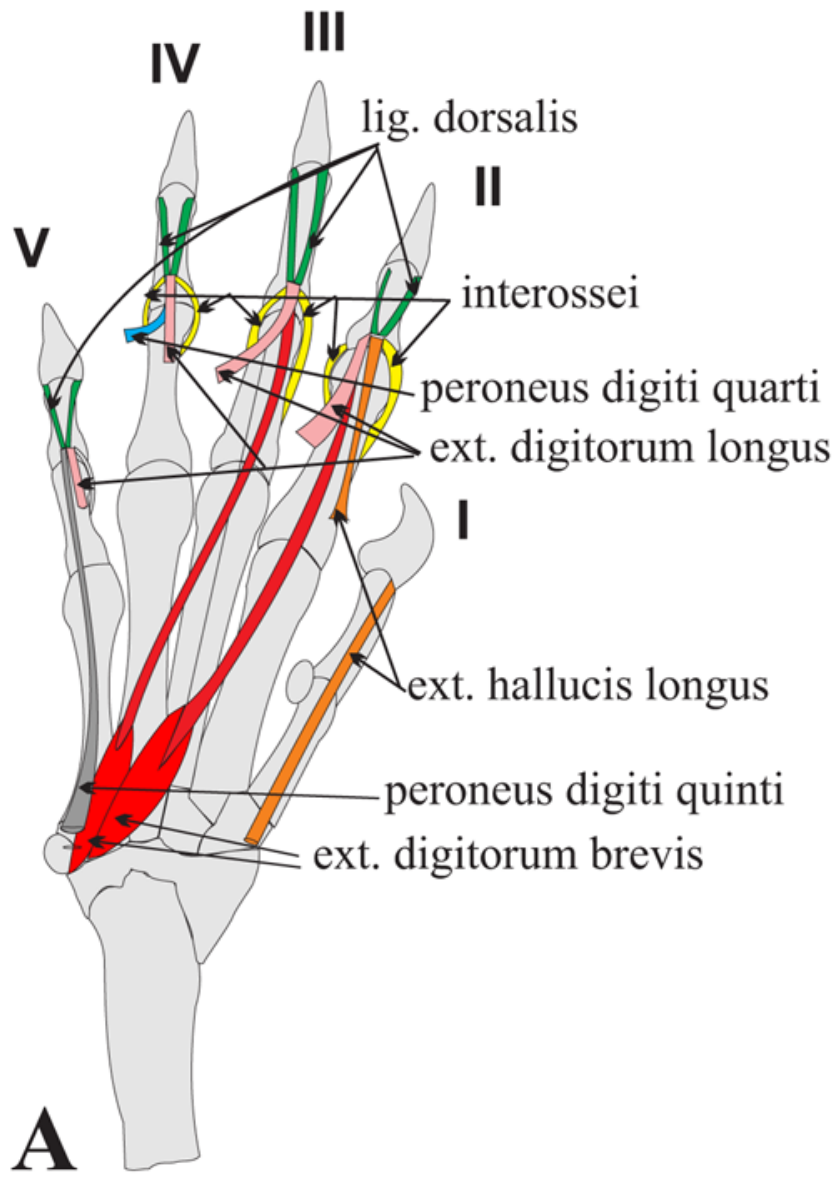

III

lig. dorsalis

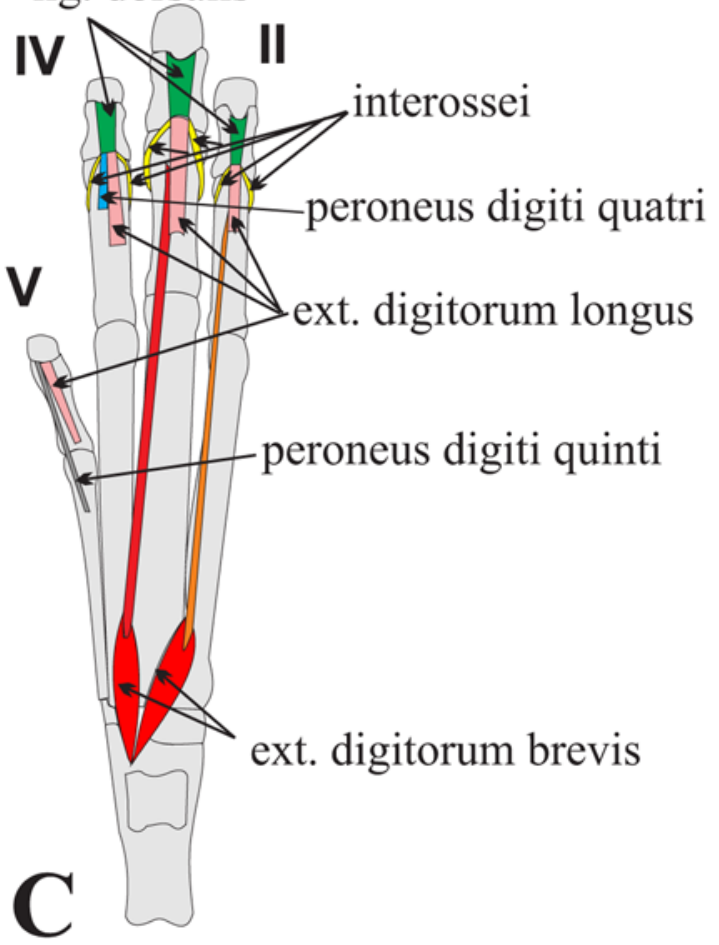

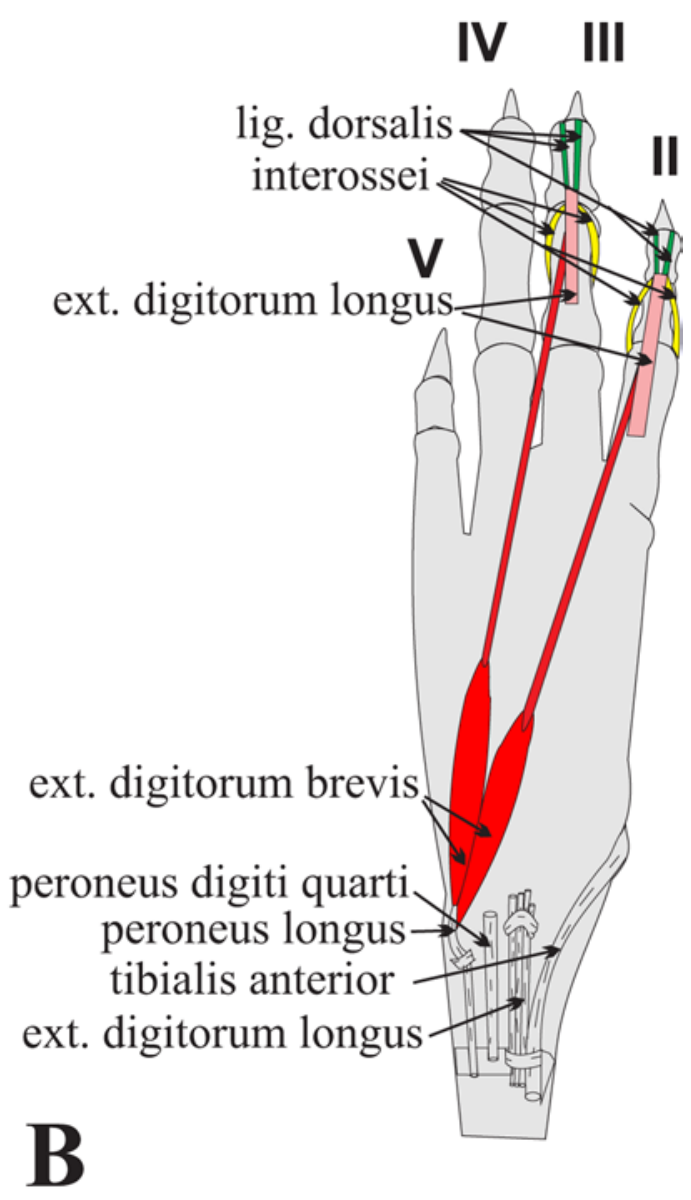

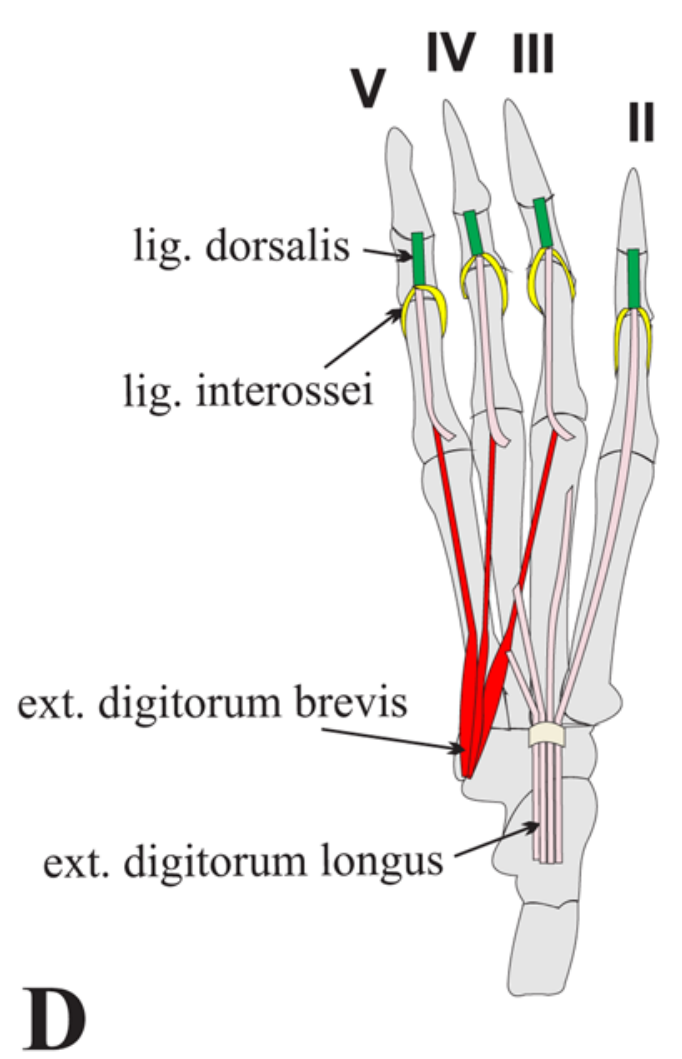


latter being originate on the dorsal surface of a tendinous plate of the $\mathrm{m}$. fl. digitorum brevis. These two abdomens terminate together in the inter-sesamoid space and form the perforating tendon of digit V. The other three abdomens are arranged similarly and originate from the edges of the tendons of the $\mathrm{m}$. fl. digitorum fibularis to digits III-V and a common tendinous plate. Then they join with the tendons of the $\mathrm{m}$. fl. digitorum brevis and insert as the typical perforating tendons.

In Chinchilla, there are three muscles located in the bases of the tendons of the $\mathrm{m}$. fl. digitorum fibularis between the digits II-III, III-IV, and IV-V (Fig. 6C). Before the insertion, the terminal tendons of the first two muscles merge into the $\mathrm{m}$. interossei medialis of digits III-IV. The third abdomen inserts on the medial side of the plantar surface of the proximal end of the second phalanx of digit V. In this case, in contrast to that in Laonastes and Ctenodactylus, the perforating tendons are not formed.

In Ochotona, these muscles are absent.

Mm. adductor (indicis proprius) digiti secundi and adductor digiti quinti (Fig. 7). In Laonastes, both muscles originate from the midline of the third metatarsal bone at the level of the proximal $2 / 3$ of its length (Fig. 7A). M. add. digiti secundi inserts on the lateral side of the first phalanx of digit II; the m. add. digiti quinti terminates on the medial side of the proximal end of the first phalanx of digit $\mathrm{V}$.

In Ctenodactylus, the $\mathrm{mm}$. adductors digiti secundi and digiti quinti originate at the base of digits III and IV by the thin tendons (Fig. 7B). They go to the proximal ends of the first phalanxes: from the lateral side on digit II and from the medial side on digit V.

In Chinchilla, there are both muscles, but they are greatly weakened, and in the form of thin muscular films insert by the transparent tendons on the medial side of the proximal end of the first phalanx of digit $\mathrm{V}$ (m. add. digiti quinti) and by the same way on the lateral side of digit II (m. add. digiti secundi) (Fig. 7C).

In Ochotona, mm. add. digiti secundi and add. digiti quinti, in compared with those of the previous forms, are stronger developed and originate from the midline of the pes plantar surface. Their insertions are the same as those of rodents (Fig. 7D).

M. abductor metatarsi V (Fig. 7). In Laonastes and Ctenodactylus, it originates on the plantar surface of the calcaneal tuber and inserts on the latero-proximal tuberculum of the Mt. V (Fig. 7A, B).

In Chinchilla, it is completely transformed into a tendon, which begins from the medial surface of the calcaneal tuber and terminates on the lateral surface of the proximal end of the Mt. V.

In Ochotona, this muscle is absent.

Mm. interossei (Figs. 5, 7). In Laonastes, there are ten muscles: by two muscles on every digit. In all other studied forms, there are eight muscles: by two muscles on every digit except the first one, which is a rudimentary digit in Ctenodactylus and is absent in Chinchilla and Ochotona. Mm. interossei originate on both sides of the metatarsalia II-V, bypass the sesamoids, and insert on the fused extensor tendons on the proximal ends of the second phalanxes of digits II-V.

M. abductor, flexor, and adductor hallucis brevis (Fig. 7). In Laonastes, there are all the three muscles. $\mathrm{Mm}$. abductor and flexor hallucis brevis originate from the internal surface of the prehallux and medial lip of the Mt. I, and terminate on the medio-proximal side of the first phalanx of the first digit (Fig. 7A). M. add. hallucis brevis originates from the midline of the second metatarsal bone at the level of the proximal $2 / 3$ of its length. The muscle inserts on the lateral side of the first phalanx of first digit.

In Ctenodactylus, there are only two muscles: $\mathrm{mm}$. flexor and adductor hallucis brevis, since the first digit is rudimentary (Fig. 7B).

In Chinchilla, all the three muscle, providing the first digit mobility, are absent as a result of its whole reduction. In Ochotona, the same state is observed.

\section{Conclusion}

The comparative morphological analysis revealed a number of features in the structure of the short muscles of the hand in Ochotona, which differ from those in the three forms of studied rodents: (1) the absence of the $\mathrm{mm}$. palmaris brevis and adductor digiti secundi; (2) the absence of the typical mm. lumbricales and the availability instead of them a tendon, which is evidently homologous to these muscles; (3) the m. abductor digiti quinti originates from the os pisiforme by means of only one belly instead of two bellies in rodents.

In the structure of the short muscles of the foot in Ochotona, such essential distinctions from rodents as the absence of the $\mathrm{mm}$. lumbricales and $\mathrm{m}$. abd. metatarsi $\mathrm{V}$ were revealed. It can be note also the formation of the three final tendons of the $\mathrm{m}$. ext. digitorum brevis instead two of those in rodents.

The structure of the $\mathrm{m}$. adductor digiti quinti in the hand and $\mathrm{mm}$. interossei in both the hand and the foot are characterized by a great similarity in all studied forms, though in Ctenodactylus, the insertions of the $\mathrm{mm}$. interossei in the hand in any way differ a little.

In four investigated forms, in Ctenodactylus gundi, Chinchilla lanigera, Ochotona macrotis and O. dauurica, in the structure of the hand and foot, a common tendency evidently connected with a similar locomotor adaptation to the rock landscapes, can be noted. In the result of the first digit reduction, the narrowing of the hand and foot are observed. With this connection it can be suggested that the adaptation to the plain landscapes in Ochotona was the secondary phenomenon. It should be emphasized that in studied forms the tendency men- 


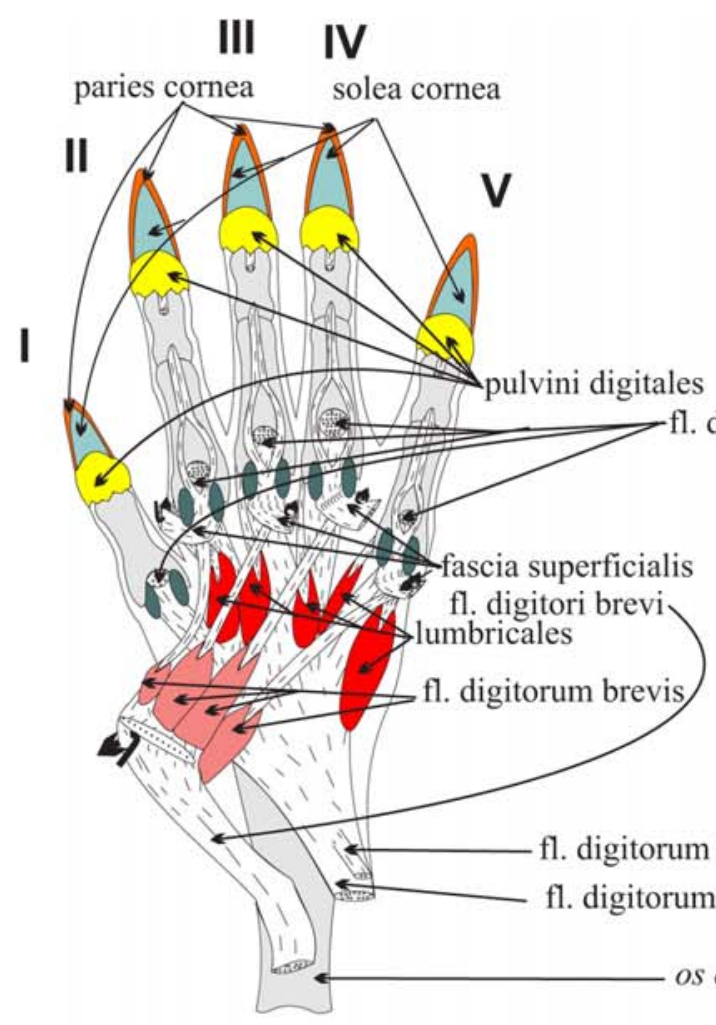

A

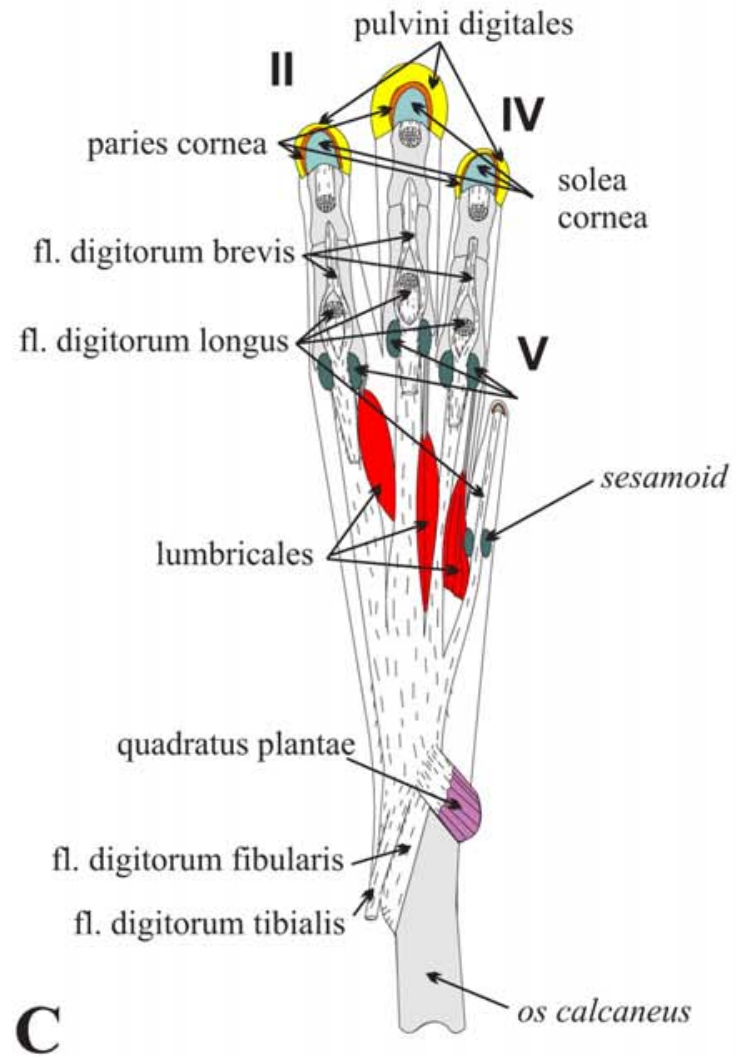

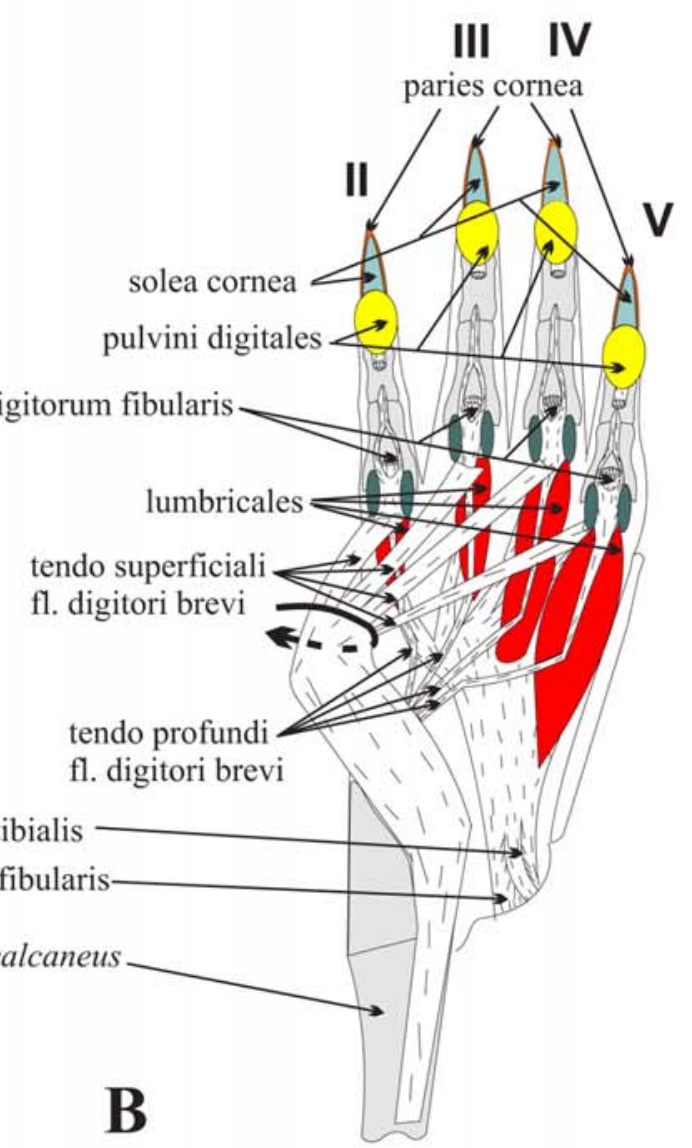

III IV

cornea

II

solea cornea

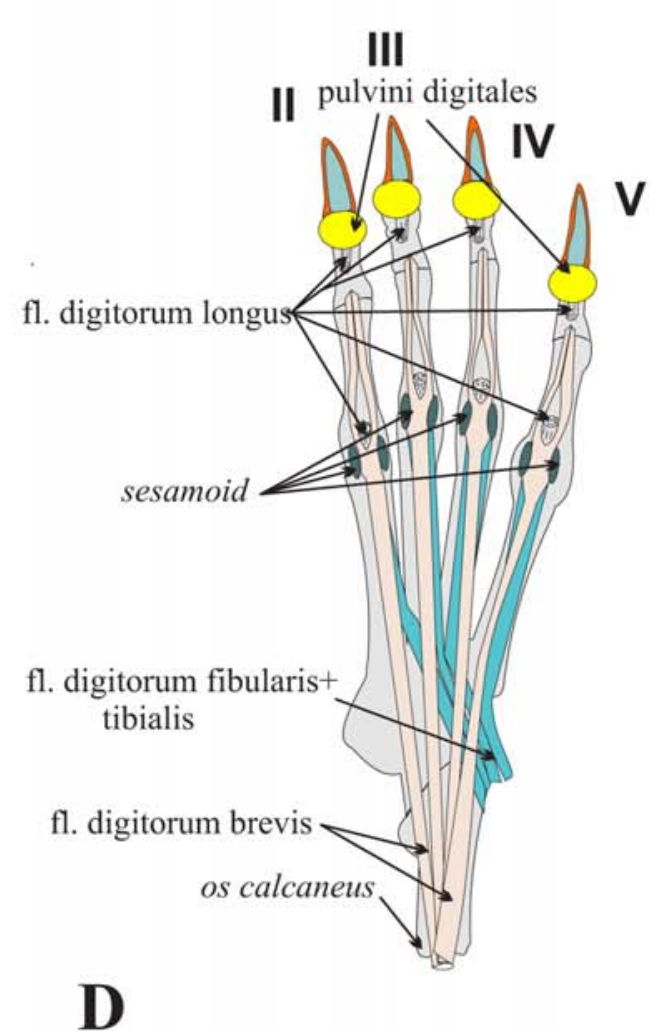


tioned above is expressed in different extent. In the hand the reduction of the first digit is most manifested in Ctenodactylus, and the same in the foot structure in Chinchilla and Ochotona. In Laonastes, there are valuable five-fingers states of the hand and foot. Therefore, the latter can be probably considered as relict rodent, which is most close to the level of the morphological specialization of the ancestor form for Ctenohystrica (Huchon et al., 2007).

The results of the comparative analysis of the short muscles confirm to the conclusion mentioned above. The one of the most essential differences in the hand and foot structure is manifested in respect of the muscles, responsible for the mobility of the first digits. Among investigated forms, Laonastes is notable by the presence of a whole set of these muscles: $\mathrm{mm}$. abductor, flexor and adductor pollicis brevis in the hand, and $\mathrm{mm}$. abductor, flexor and adductor hallucis brevis in the foot. However, it is necessary to note a single undifferentiated origin of these muscles in its hand.

In Ctenodactylus, the first digit of the hand is rudimentary, and all the three muscles, providing its mobility, are absent. In the foot, the first digit is weakly developed, and there are only $\mathrm{mm}$. flexor and adductor hallucis brevis.

In Chinchilla, the first digit in the hand is weaker developed than that in Laonastes, but there are all the three muscles responsible for its mobility. In the foot, on the contrary, the all muscles of the first digit are absent with the connection of its whole reduction. In Ochotona, the very similar state is observed, however in the hand the $\mathrm{m}$. abductor pollicis brevis is absent.

Among the studied rodents, the m. abductor digiti quinti in the hand is characterized by a great similarity, but the structure of the $\mathrm{m}$. palmaris brevis, on the contrary, varies.

In regard to the mm. lumbricales of the hand, the most simple and probably the most primitive their structure is observed in Laonastes. In contrast to that, the most advanced state of these muscles is noted in Ctenodactylus; Chinchilla in this relation takes an intermediate position.

The data obtained on the topography and attachment of the lateral belly of the mm. lumbricales in the hand, allow us to follow one of the developmental paths of the forth final tendon of the $\mathrm{m}$. fl. digitorum sublimis in rodents. The matter is that in the majority of marsupials, rodents, and insectivores, the $\mathrm{m}$. fl. digitorum sublimis has three final tendons, terminating on the three middle digits (Dobson, 1882; Parsons, 1894, 1898; Howell, 1926; Green, 1935; Reed, 1951; Rinker, 1954; Gambaryan, 1960; Jullien, 1967; Jouffroy, 1971; Zherebtsova, 2001). In all investigated rodents, the fourth tendon as derivative of the $\mathrm{mm}$. lumbricales appears. Their separate belly is closely associated with a common tendinous plate of the $\mathrm{m}$. fl. digitorum profundus and the lateral tendon of the $\mathrm{m}$. fl. digitorum sublimis. This belly terminates as a typical perforating tendon, simulating the fourth tendon of the $\mathrm{m}$. fl. digitorum sublimis to digit $\mathrm{V}$. In primates, the $\mathrm{m}$. fl. digitorum sublimis has four or, more seldom, five its own final tendons. Apparently, the lateral and medial tendons of the $\mathrm{m}$. fl. digitorum sublimis in primates are derivatives of the mm. lumbricales.

Besides, Laonastes differs from other two rodents by the region of the origin of the $\mathrm{mm}$. adductors digiti secundi and digiti quinti, $m$. fl. digitorum brevis in the foot. The latter in Laonastes forms three final tendons instead four of those in Ctenodactylus and Chinchilla.

In regard to other short muscles of the foot, it is necessary to note a similar structure of the $\mathrm{m}$. abductor metatarsi V in Laonastes and Ctenodactylus. In Chinchilla, this muscle is transformed completely into a tendon, and in Ochotona, it is absent. A greater similarity between Laonastes and Ctenodactylus is also observed in region of the initial attachment of the m. ext. digitorum brevis and formation of the perforating tendons of the mm. lumbricales. In Chinchilla, such tendons are not formed. At the same time the development of the m. quadratus plantae is a common feature of Laonastes and Chinchilla, and, on the contrary, its absence is characteristic of Ctenodactylus and Ochotona.

The wide discussion of all revealed features of the short muscles of the hand and foot in the three studied forms of rodents and Ochotona will be planned in the next communication on the base of the new morphofunctional data received.

ACKNOWLEDGEMENTS. The authors would like to thank Dr. Alexei V. Abramov (ZIN of RAS, Saint Petersburg) for the opportunity to examine the unique material on Laonastes aenigmamus collected in Laos. Special thanks to Vladimir V. Platonov for help in the work with figures and "American Journal Experts" for the correction of English. We are especially grateful to Dr. Elena G. Potapova (IPEE of RAS, Moscow) and Dr. Yuri F. Ivlev (IPEE of RAS, Moscow) for reviewing the manuscript and constructive recommendations. The study was supported by Russian Foundation for Basic Research (grant No 10-04-00973).

\section{References}

Dawson M.R., Marivaux L., Li Ch., Beard K.Ch. \& Metais G. 2006. Laonastes and the "Lazarus effect" in recent mammals // Science. Vol.311. P.1456-1458.

Dieterlen F. 2005. Suborder Hystricomorpha. Infraorder Ctenodactylomorphi // Wilson D.E. \& Reeder D.M. (eds.). Mammal Species of the World. A Taxonomic and Geographic Reference. Third edition. Vol.2. Baltimore: Johns Hopkins University Press. P.1536-1537.

Dobson G.E. 1882. A Monograph of the Insectivora, Systematic and Anatomical. Pt. I. London: John van Voorst. $172 \mathrm{p}$. 

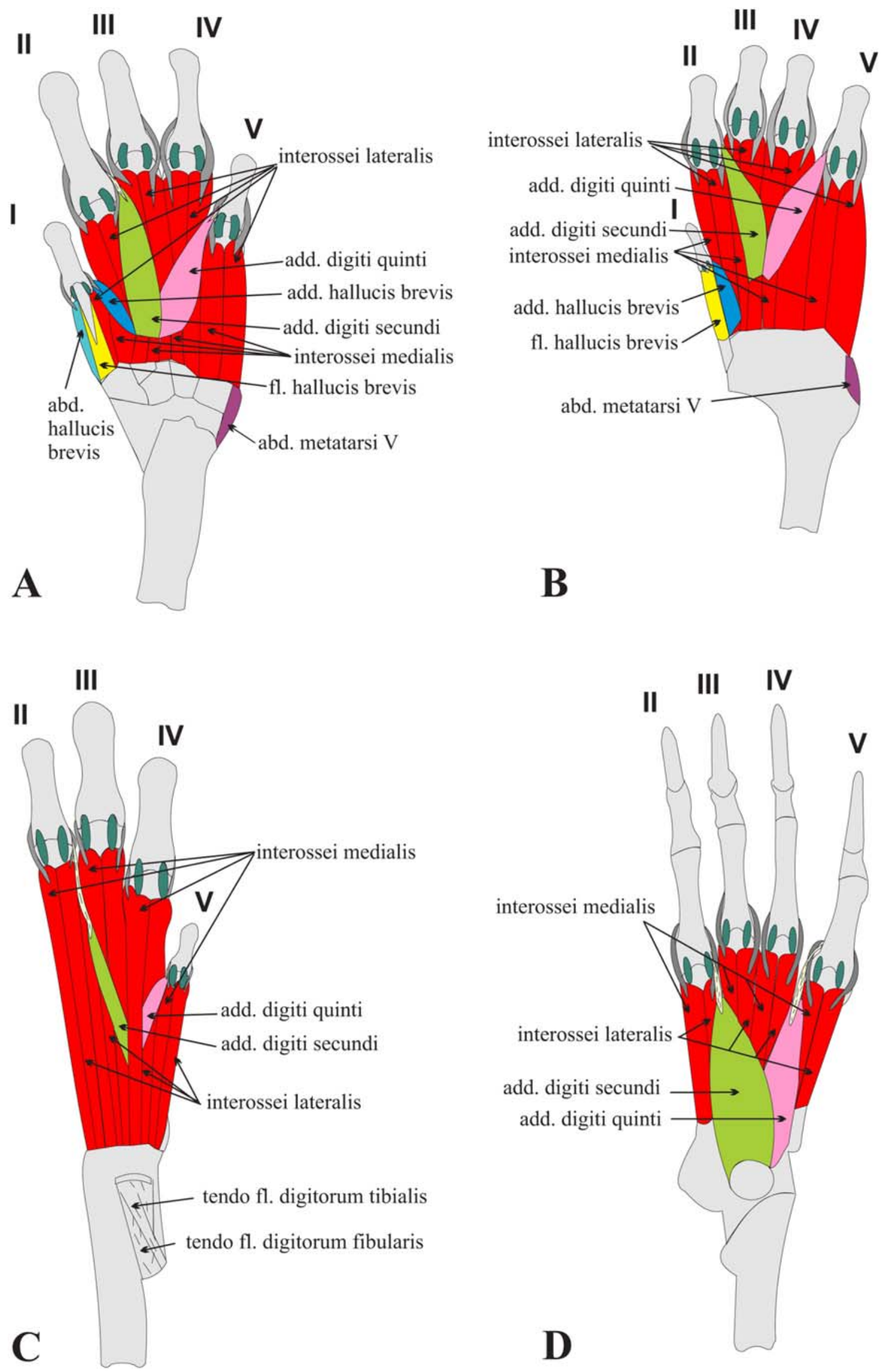
Gambaryan P.P. 1960. [Adaptive features of the locomotor organs in fossorial mammals]. Erevan: Izdatel'stvo AN Armyanskoi SSR. 195 p. [in Russian]

Gambaryan P.P., Zherebtsova O.V. \& Perepelova A.A. 2013. Comparative analysis of forelimb musculature in Laonastes aenigmamus (Rodentia: Diatomyidae) // Proceedings of the Zoological Institute RAS. Vol.317. No.3. P. 226-245.

Green E.C. 1935. Anatomy of the rat // Transactions of the American Philosophical Society, N.S. Vol.27. P.1-370.

Hoffmann R.S. \& Smith A.T. 2005. Order Lagomorpha. Family Ochotonidae // Wilson D.E. \& Reeder D.M. (eds.). Mammal Species of the World. A Taxonomic and Geographic Reference. Third edition. Vol.1. Baltimore: Johns Hopkins University Press. P.185-193.

Howell A.B. 1926. Anatomy of the Wood Rat. Baltimore: The Williams and Wilkins. $230 \mathrm{p}$.

Huchon D., Chevret P., Jordan U., Kilpatrick C.W., Ranwez V., Jenkins P.D., Brosius J. \& Schmitz J. 2007. Multiple molecular evidences for a living mammalian fossil // Proceedings of the National Academy of Sciences of the USA. Vol.104. P.7495-7499.

Jenkins P.D., Kilpatrick C.W., Robinson M.F. \& Timmins R.J. 2005. Morphological and molecular investigations of a new family, genus and species of rodent (Mammalia: Rodentia: Hystricognatha) from Lao PDR // Systematics and Biodiversity. Vol.2. No.4. P.419-454.

Jouffroy F.-K. 1971. Mammifères. Musculature des members // Traité de Zoologie: Anatomie, Systématique, Bi- ologie. Vol.16. No.3. P.1-476.

Jullien R. 1967. Musculature du member anterieur chez les principaux types d'insectivores // Memoires du Museum National d'Histoire Naturelle, Ser.A, Zoology. Vol.48. No.1. P.1-68.

Parsons F.G. 1894. On the myology of the sciuromorphine and hystricomorphine rodents // Proceedings of the Zoological Society, London. P.251-296.

Parsons F.G. 1898. The limb myology of Gymnura rafflesii // Journal of the Anatomy and Physiology. Vol.32. P.312324.

Reed C.A. 1951. Locomotion and appendicular anatomy in three soricoid insectivores // American Midland Naturalist. Vol.45. No.3. P.513-671.

Rinker G.C. 1954. The comparative myology of the mammalian genera Sigmodon, Oryzomys, Neotoma, and Peromyscus (Cricetinae), with remarks of their intergeneric relationships // Miscellaneous Publications Museum of Zoology, University of Michigan. No.83. P.1-124.

Woods C.A. \& Kilpatrick C.W. 2005. Suborder Hystricomorpha. Infraorder Hystricognathi // Wilson D.E. \& Reeder D.M. (eds.). Mammal Species of the World. A Taxonomic and Geographic Reference. Third edition. Vol.2. Baltimore: Johns Hopkins University Press. P.1538-1600.

Zherebtsova O.V. 2006. [Comparative morphological analysis of the forelimb musculature in erinaceids (Erinaceidae, Insectivora)] // Zoologicheskii Zhurnal. Vol.80. No.5. P.586-598 [in Russian, with English summary].

Figure 7. The pes muscles (left) from the plantar side (the deep layer): A — Laonastes aenigmamus; B — Ctenodactylus gundi; C - Chinchilla lanigera; D - Ochotona dauurica. 